\title{
ANALISIS PENGARUH KOMPENSASI DAN BENEFIT TERHADAP KEPUASAN KERJA PEGAWAI HONORER DIREKTORAT JENDERAL KEKAYAAN INTELEKTUAL
}

\section{Eka Kurniawan, Kusumo Bintoro}

Universitas Bakrie, Jakarta, Indonesia

Email: eka.kurniawan@dgip.go.id, kusumo.bintoro@bakrie.ac.id

\begin{abstract}
Abstrak
Lahirnya Undang-Undang Nomor 5 Tahun 2014 Tentang Aparatur Sipil Negara, menjadi dasar dari hadirnya pegawai pemerintah dengan status kontrak dalam jangka waktu tertentu. Berdasarkan undang-undang tersebut saat ini komposisi aparatul sipil negara tidak hanya terdiri dari unsur pegawai negeri namun juga pegawai pemerintah dengan status kontrak. Secara garis besar terdapat perbedaan yang mencolok pada hak dan kewajiban dari kedua status tersebut Dimana kesejahteraan dan benefit tambahan pegawai negeri telah terjamin besaran dan jenisnya serta diatur dalam sebuah perangkat hukum yang jelas. Sementera pegawai kontrak kedua hak tersebut nilainya jauh lebih kecil dengan ruang lingkup pekerjaan yang sama. Tujuan penelitian ini adalah untuk mengetahui pengaruh kompensasi dan Benefit terhadap Kepuasan Kerja Pegawai Pemerintah Non Pegawai Negeri di lingkungan Direktorat Jenderal Kekayaan Intelektual. Metode penelitian yang digunakan adalah kuantitaif dengan pendekatan survey. Key informant dalam penelitian ini adalah PPNPN Direktorat Jenderal Kekayaan Intelektual Teknik analisis yang digunakan adalah analisis regresi berganda terhadap variabel tetap kepuasan kerja dan variabel bebas kompensasi dan benefit. Hasil yang dihasilkan adalah bahwa kompensasi dan benefit adalah memiliki pengaruh positif terhadap kepuasan kerja pegawai pemerintah non pegawai negeri sipil dilingkungan Ditjen Kekayaan Intelektual. Adapun saran penulis kepada Ditjen Kekayaan Intelektual adalah agar sesegera mungkin mendorong sebuah sistem kompensasi dan benefit yang baik dan dengan didukung oleh dasar hukum yang baik agar tidak terjadi permasalahan dikemudian hari.
\end{abstract}

Kata Kunci: kompensasi; benefit; kepuasan kerja regresi berganda

\section{Abstract}

The enactment of Law Number 5 of 2014 concerning State Civil Apparatus, became the basis for the presence of government employees with contract status within a certain period of time. Based on this law, the current composition of the state civil apparatus does not only consist of civil servants but also government employees with contract status. Broadly speaking, there are striking differences in the rights and obligations of the two statuses. The welfare and additional benefits of civil servants have been guaranteed in terms of size and type and are regulated in a clear legal instrument. Meanwhile, contract employees of both rights are much

How to cite:

E-ISSN:

Published by:
Kurniawan. E \& Bintaro, K. (2021) Analisis Pengaruh Kompensasi dan Benefit Terhadap Kepuasan Kerja Pegawai Honorer Direktorat Jenderal Kekayaan Intelektual. Syntax Literate: Jurnal Ilmiah Indonesia, 6(10). http://dx.doi.org/10.36418/ Syntax-Literate.v6i10.4267 2548-1398

Ridwan Institute 
smaller in value with the same scope of work. The purpose of this study was to determine the effect of compensation and benefits on job satisfaction of non-civil servant government employees in the Directorate General of Intellectual Property. The research method used is quantitative with a survey approach. The key informant in this study is the PPNPN Directorate General of Intellectual Property. The analytical technique used is multiple regression analysis on the fixed variable job satisfaction and the independent variables of compensation and benefits. The result is that compensation and benefits have a positive effect on job satisfaction of non-civil servant government employees within the Directorate General of Intellectual Property. The author's suggestion to the Directorate General of Intellectual Property is to immediately encourage a good compensation and benefit system and supported by a good legal basis so that problems do not occur in the future.

Keywords: compensation; benefits; job satisfaction multiple regression

Received: 2021-09-20; Accepted: 2021-10-05; Published: 2021-10-20

\section{Pendahuluan}

Salah satu sumber pendapatan masyarakat untuk meningkatkan kesejahteraan adalah Pemberdayaan Usaha Kecil dan Menengah yang mampu menjadi pendorong pertumbuhan kegiatan ekonomi masyarakat (Saputri, 2014), keberhasilan menentukan kebijakan yang tepat dari proses penentuan produk, harga, promosi serta saluaran distribusi yang efektif merupakan Keberhasilan UMKM juga (Dimas Hendika Wibowo \& Arifin, 2015),di sisi lain kinerja pelaku usaha diarahkan untuk menghasilkan produk bermutu dengan harga yang kompetitif (Marwoto, 2014), untuk itu aplikasi inovasi harus di gunakan sebagai upaya peningkatan daya saing, (Pridayanti, 2014),karena di dalm dunia perbisnisan Daya saing merupakan suatu upaya yang harus dilakukan oleh pelaku usaha/ekonomi agar tetap eksis dalam menjalankan kegiatannya (Asmara \& Rahayu, 2013).

Sumber daya manusia adalah salah satu faktor yang memiliki peranan kunci dalam sebuah organisasi, baik dalam sebuah organisasi yang besar ataupun organisasi dalam skala kecil. Sumber daya manusia dalam sebuah organisasi memiliki peranan dalam membangun karakter dan budaya dari suatu organisasi. Peranan utama sebagai motor pengerak dari organisasi dan interaksi diantara pegawai pada akhirnya menciptakan sebuah budaya tersendiri yakni budaya kerja organiasasi. Budaya organisas dihasilkan oleh interaksi diantara pegawai yang dating dari latarbelakang yang berbeda namun semuanya bahu membahu dalam mencapai tujuan organisasi. Umumnya budaya organisasi telah ditetapkan oleh top management dalam struktur organisasi dengan tujuan agar hal ini adalah sesuatu yang terstandar dengan baik dan tidak berubah meskipun terjadi pergantian SDM dalam organisasi tersebut. Prinsipnya adalah setiap orang baru yang bergabung dalam organisasi tersebut harus dapat menyesuaikan dirinya dengan budaya yang ditetapkan. Sehingga tidak menganggu kinerja organisasi dimasa yang akan dating. 
Menurut (Moeheriono \& Si, 2012), "Kinerja atau performance merupakan gambaran mengenai tingkat pencapaian pelaksanaan suatu program kegiatan atau kebijakan dalam mewujudkan sasaran, tujuan, visi dan misi organisasi yang dituangkan melalui perencanaan strategis suatu organisasi". Dan menurut (Wibowo, 2013) "Kinerja mempunyai makna lebih luas, bukan hanya menyatakan hasil kerja, tetapi juga bagaimana proses kerja berlangsung”. Kinerja adalah tentang apa yang dikerjakan dan bagaimana cara mengerjakannya. Seorang pegawai akan baik, jika pegawai mempunyai keahlian yang tinggi, kesediaan untuk bekerja, adanya kompensasi yang layak dan mempunyai harapan masa depan.

Sedangkan menurut pendapat (Rivai \& Juavani, 2013) kinerja adalah perilaku nyata yang ditampilkan setiap orang sebagai prestasi kerja yang dihasilkan oleh karyawan sesuai dengan perannya dalam perusahaan. Berdasarkan pengertian di atas dapat dipahami bahwa kinerja merupakan hasil dari suatu perbuatan atau tindakan nyata, dalam rangka meningkatkan prestasi sesuai dengan tujuan yang ditetapkan berkaitan dengan tugas dan tanggung jawab yang dilakukan dalam suatu pekerjaan sesuai dengan profesi.

Kepuasan kerja pegawai diekspresikan dengan antusias yang tinggi, disiplin, motivasi yang bagus, kesediaan belajar dan menerima pelajaran dari orang lain dan sebagainya. Fleisman dan Bass dalam (W. Wibowo, 2014) mengemukakan kepuasan kerja merupakan suatu tindakan efektif pegawai terhadap pekerjaannya. Kepuasan kerja tersebut dianggap sebagai hasil pengalaman pegawai dalam kaitannya dengan penilaian terhadap diri sendiri seperti apa yang dikehendaki atau diharapkan dari pekerjaannya, sehingga tingkat kepuasan kerja merupakan suatu sikap dan umpan balik pegawai terhadap pekerjaannya. Kepuasan pegawai pada dasarnya sangatlah individualistis dan merupakan hal yang sangat tergantung pada pribadi masing-masing pegawai. Namun demikian terdapat beberapa faktor yang berhubungan dengan kepuasan pegawai seperti, faktor kepuasan sosial seperti: interaksi antara pegawai, antara pegawai dengan atasan dan antara pegawai dengan pegawai yang berbeda jenis pekerjaan. Indikator kepuasan fisik seperti kondisi fisik kantor, dan kondisi fisik sesama pegawai. Adapun faktor kepuasan finansial adalah sesuatu yang berhubungan dengan pemenuhan jaminan dan kesejahteraan (gaji, upah, lembur, THR) pegawai. Sementara Menurut Handoko dalam (Yulfiana, Yuliana, \& Suyuthie, 2015) Kepuasan kerja adalah, "Keadaaan emosional yang menyenangkan atau tidak menyenangkan dengan mana para karyawan memandang pekerjaan mereka".

Kompensasi merupakan salah satu cara/strategi untuk memotivasi pegawai pada suatu organisasi. menurut (Suwati, 2013) Kompensasi merupakan istilah luas yang berkaitan dengan imbalan-imbalan finansial (financial rewards) yang diterima pegawai melalui hubungan kepegawaian mereka dalam sebuah organisasi perusahaan. Dengan pemberian kompensasi yang proporsional maka diharapkan lembaga pemerintahan seperti Dinas Perhubungan memberikan sebuah bentuk kebijakan sehingga pegawai merasa pimpinan menaruh perhatian terhadap kesejahteraan bawahannya sehingga mereka bersedia secara sukarela untuk menjaga eksistensinya di dalam bekerja. 
Pemberian program kompensasi dan benefit diharapkan mampu untuk memenuhi kebutuhan pokok pegawai dan keluarganya serta juga sebagai bentuk dorongan untuk meningkatkan semangat dan motivasi.

Kompensasi merupakan salah satu tujuan yang ingin dicapai seseorang dalam bekerja. Menurut (Mathis \& Jackson, 2011) kompensasi merupakan faktor penting yang mempengaruhi bagaimana dan mengapa orang-orang bekerja pada suatu organisasi bukan organisasi lainnya. Sedangkan (Dessler, 2011) menyatakan kompensasi merupakan semua bentuk pembayaran atau imbalan bagi karyawan sebagai hasil dari pekerjaan mereka.

Kompensasi atau balas jasa dapat diperhitungkan sebagai upah uang/upah nyata (riil) seperti menurut Flippo dalam (Hasibuan \& Hasibuan, 2016) adalah sebagai berikut: Harga untuk jasa-jasa yang telah diberikan oleh seseorang kepada orang lain atau kata lain tiap pembayaran baik berupa uang maupun barang yang diterima oleh karyawan sebagai balas jasa terhadap tenaga dan pikiran yang disumbangkan kepada perusahaan.

Program kompensasi/balas jasa ini umumnya bertujuan untuk kepentingan perusahaan, karyawan dan pemerinyah/ masyarakat. Supaya tujuan ini tercapai dan memberikan kepuasan bagi semua pihak, hendaknya program kompensasi ditetapkan berdasarkan prinsip adil dan layak, Undang-Undang perburuhan, serta memperhatikan internal dan eksternal konsistensi.

Pada penelitian ini akan diharapkan dapat memberikan sebuah gambaran baru dari tentang bagaimana pengaruh kompensasi dan benefit yang diberikan oleh instansi pemerintah terhadap ASN yang bekerja diinstansi tersebut setelah berlakunya UndangUndang Nomor 5 Tahun 2014 Tentang Aparatur Sipil Negara. Dimana berdasarkan Undang-Undang tersebut terdapat (2) dua jenis ASN yang saat ini diakui yakni pegawai negeri sipil dan pegawai kontrak, serta didalamnya juga telah diatur tentang hak dan kewajiban serta imbal jasa yang akan diterima oleh masing-masing dari kedua jenis ASN tersebut. Prakteknya tentunya akan berbeda dengan status pegawai tetap dan pegawai kontrak pada sector swasta, hal ini tentunya tidak hanya karena perbedaan jenis atau bidang usahanya dimana instansi pemerintah adalah mengedepankan pelayanan publik sementara sector swasta lebih mengedepankan aspek bisnis dalam rangka meningkatkan laba dan nilai perusahaan dimata investor dan masyarakat. Selain itu pegawai kontrak pada sector swasta umumnya dapat diangkat untuk menjadi pegawai tetap pada perusahaan tersebut. Sedangkan disisi kompensasi dan benefit adalah lebih dihubungkan dengan performa karyawan, pengalaman dan kompetensi karyawan serta kontribusinya terhadap peningkatan laba dan nilai perusahaan. Sehingga nilai kompensi dan benefit nilainya tidak jauh berbeda dengan pegawai tetap atau bahkan dapat melebihi besaran yang diterima oleh pegawai tetap. Hal ini menjadi sesuatu yang menarik tentang bagaimana kedua factor tersebut mempengaruhi kinerja pegawai kontrak di intansi pemerintah yang besaran kompensasi dan benefitnya adalah tetap dan tidak dipengaruhi oleh bagaimana output pekerjaan yang dihasilkan, pengalaman kerja sebelumnya, kompetensi yang dimiliki maupun kontribusinya terhadap kinerja instansi 
pemerintah tersebut. Program kompensasi pegawai meliputi gaji tetap, gaji/upah di luar jam kerja, Pemberian insentif dan adanya tunjangan yang mendukung kesejahteraan pegawai. Upah merupakan komponen kompensasi yang memegang peranan penting dalam upaya meningkatkan kinerja pegawai. Upah yang layak yang diberikan kepada pegawai merupakan salah satu faktor pendorong bagi pegawai untuk menyelesaikan pekerjaannya sesuai dengan kriteria yang diinginkan perusahaan. Dengan adanya upah, para pegawai termotivasi untuk mencapai tujuan organisasi. Namun sebaliknya apabila para pegawai merasa tidak puas atas upah yang telah diberikan rumah sakit maka akan berdampak negatif pada kinerja pegawai sehingga akan berdampak negatif pula pada kinerja dinas perhubungan. Insentif dan tunjangan diberikan untuk memotivasi pegawai meningkatkan kinerjanya, bentuk dari keduanya bermacam-macam tergantung dari kebijaksanaan perusahaan. Insentif diberikan sebagai bentuk imbalan atas prestasi yang dicapai pegawai di luar jam kerjanya dan dapat dinilai dengan uang. Sedangkan tunjangan diberikan untuk mendukung kesejahteraan pegawai selama dalam rumah sakit. Bentuk tunjangan bermacam-macam di antaranya adanya tunjangan kesehatan, Tunjangan Hari Raya (THR), pemberian asuransi tenaga kerja, dan lain sebagainya. Melalui hasil penelitian ini diharapkan nantinya dapat digunakan oleh instansi yang menjadi objek penelitian dalam menyusun skema kompensasi dan benefit yang dapat memacu kinerja pegawai kontraknya maupun pegawai negeri sehingga lebih terpacu dalam bekerja dan pada akhirnya akan membantu instansi tersebut untuk meningkatkan output pekerjaan dalam melaksanakan pelayanan publik kepada masyarakat dibidang kekayaan intelektual.

\section{Metode Penelitian}

Peneliti menggunakan metode penelitian kuantitatif dengan menggunakan pendekatan survey. Menurut Sugiyono (Sugiyono, 2017) Metode kuantitatif dapat diartikan sebagai "Metode penelitian yang berlandaskan pada filsafat positivisme, digunakan untuk meneliti pada populasi atau sampel tertentu, pengumpulan data menggunakan instrumen penelitian, analisis data bersifat kuantitatif atau statistik, dengan tujuan untuk menguji hipotesis yang ditetapkan."

\section{A. Objek Penelitian}

Objek penelitian ini difokuskan pada faktor kompensasi dan benefit yang mempengaruhi kinerja seorang Aparatur Sipil Negara khususnya pegawai kontrak di lingkungan Kementerian Hukum dan Hak Asasi Manusia. Sedangkan unit analisisnya adalah Direktorat Jenderal Kekayaan Intelektual. Adapun waktu pelaksanaan kegiatan penelitian adalah Desember 2020-Januari 2021.

\section{B. Teknik Analisis Data}

Alat analisis yang digunakan dalam penelitian ini adalah analisis regresi berganda, penggunaan analisis regresi berganda dilakukan untuk menghitung naik turunnya keadaan variabel terikat. Hal ini dapat dilakukan bila memiliki dua atau lebih variabel bebas yang dinaik turunkan nilainya dalam kata lain prediktor dimanipulasi, dengan kata lain analisis regresi berganda dapat digunakan bila 
sebuah variabel terikat memiliki minimal dua variabel bebas dengan rumus sebagai berikut (Sugiyono, 2017):

$\mathrm{Y}=\mathrm{a}+\mathrm{b}_{1} \mathrm{X}_{1}+\mathrm{b}_{2} \mathrm{X}_{2}+\mathrm{b}_{3} \mathrm{X}_{3}+\mathrm{b}_{4} \mathrm{X}_{4}$

Teknik pengumpulan data yang digunakan dalam penelitian ini adalah dengan menyebarkan angket atau kuesioner kepada pegawai honorer di lingkungan Direktorat Jenderal Kekayaan Intelektual untuk mengetahui bagaimana kompensasi dan benefit Mempengaruhi Kinerja Pegawai Kontrak dilingkungan Kementerian Hukum dan Hak Asasi Manusia adapun teknik pengolahan data menggunakan Analisis Regresi Berganda menggunakan Software SPSS Statistics 26.

Jumlah responden yang dilibatkan dalam penelitian ini sebesar 172 responden, perhitungan untuk mendapatkan jumlah responden menggunakan Rumus Slovin dengan perhitungan total populasi pegawai pada Direktorat Jenderal Kekayaan Intelektual sejumlah 300 orang, Confidence Level sebesar 95\% dan Margin of Error sebesar $5 \%$.

\section{Hasil dan Pembahasan}

\section{A. Hasil Penelitian}

1. Uji Validitas dan Reliabilitas

Tabel 1

Uji Validitas dan Reliabilitas

\begin{tabular}{|c|c|c|c|c|c|}
\hline \multirow[b]{2}{*}{ Variabel } & \multirow[b]{2}{*}{ Item } & \multicolumn{2}{|c|}{ Validitas } & \multicolumn{2}{|c|}{ Reliabilitas } \\
\hline & & $\begin{array}{l}\mathrm{r} \\
\text { hitung }\end{array}$ & Keterangan & alpha & Keterangan \\
\hline \multirow{3}{*}{ Kompensasi } & $\mathrm{X} 1 \_1$ & 0.692 & Valid & 0.801 & Reliabel \\
\hline & $X 1 \_2$ & 0.539 & Valid & & \\
\hline & $X 1 \_3$ & 0.717 & Valid & & \\
\hline \multirow{2}{*}{ Benefit } & $X 1 \_4$ & 0.619 & Valid & 0.752 & Reliabel \\
\hline & X1_5 & 0.619 & Valid & & \\
\hline \multirow{5}{*}{$\begin{array}{c}\text { Kepuasan } \\
\text { kerja }\end{array}$} & Y1_1 & 0.773 & Valid & 0.854 & Reliabel \\
\hline & Y1_2 & 0.631 & Valid & & \\
\hline & Y1_3 & 0.567 & Valid & & \\
\hline & Y1_4 & 0.590 & Valid & & \\
\hline & Y1_5 & 0.815 & Valid & & \\
\hline
\end{tabular}

Dari hasil pengujian reliabilitas pada variabel Budaya Organisasi, Human Capital Management, Pengembangan Karir, Kepemimpinan dan Kinerja Pegawai didapat nilai Alpha Cronbach di atas 0,700 dengan demikian instrumen penelitian dinyatakan reliabel. 
Eka Kurniawan, Kusumo Bintoro

2. Uji Normalitas

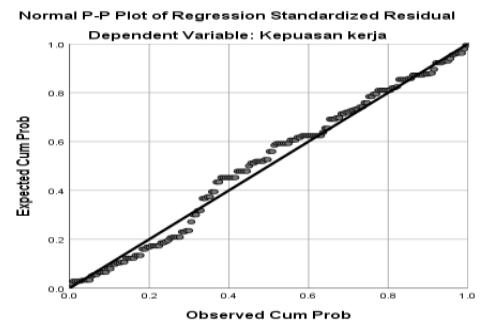

Gambar 1

Uji Normalitas

Melihat grafik sebagaimana terlihat diatas dapat diketahui bahwa plot data mengikuti garis diagonalnya, sehingga dapat diambil sebuah kesimpulan bahwa data yang digunakan dalam penelitian ini mengikuti distribusi normal.

3. Uji Heteroskedastisitas

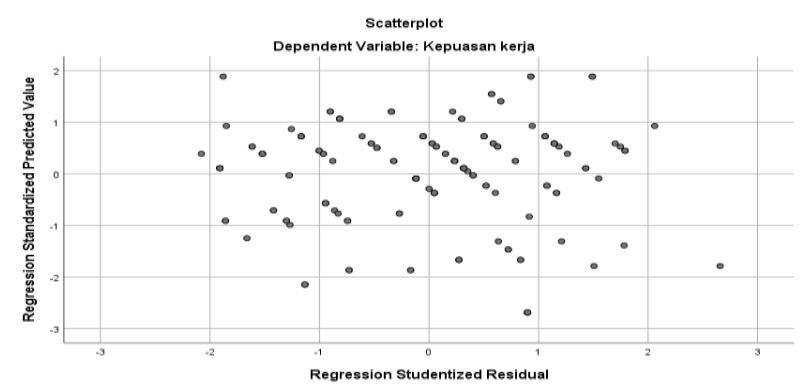

Gambar 2

Uji Heteroskedastisitas

Berdasarkan gambar scater plot di atas, dapat dilihat bahwa titik-titik menyebar secara acak dan tidak membentuk sebuah pola tertentu atau dengan kata lain menyebar diatas dan dibawah angka 0 pada sumbu $\mathrm{Y}$, sehingga dapat disimpulkan terhadap data yang diteliti tidak ditemukan heteroskedastisitas.

4. Uji Multikolinieritas

Tabel 2

Uji Multikolinieritas

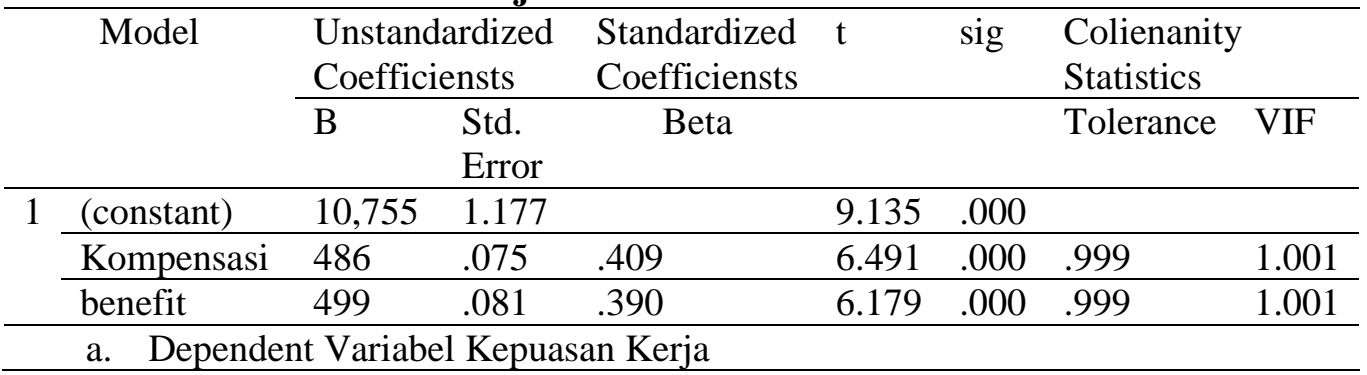


Berdasarkan hasil pengolahan, diketahui bahwa variabel bebas Kompensasi dan Benefit memiliki nilai tolerance masing-masing lebih besar dari 0,10 dan nilai VIF kurang dari 10, sehingga dapat disimpulkan bahwa dalam model regresi tersebut tidak terjadi multikolinieritas.

5. Uji Autokorelasi

Tabel 3

Uji Autokorelasi

\begin{tabular}{lllllll}
\hline Model & $\mathrm{R}$ & R Square & $\begin{array}{l}\text { Adjused } \\
\text { Square }\end{array}$ & $\begin{array}{l}\text { Std. } \\
\text { Of Eror } \\
\text { Estimate }\end{array}$ & $\begin{array}{l}\text { Dubin } \\
\text { Waston }\end{array}$ \\
\hline 1 & 573 & 328 & 320 & 1.38643 & 2.010 \\
\hline
\end{tabular}

a .Predictors : (Constant), Benefit, Kompensasi

b. Dependent Variabel Kepuasan Kerja

Berdasarkan hasil pengolahan data diketahui nilai Durbin-Watson sebesar 2,010. Nilai tersebut berada diantara du $(1,77)$ sampai 4-du $(2,23)$, sehingga dapat disimpulkan tidak ada autokorelasi. Berdasarkan uji asumsi klasik di atas, diketahui bahwa semua pengujian data tidak ditemukan adanya pelanggaran asumsi klasik, sehingga data dapat dianalisis menggunakan analisis regresi linier berganda.

\section{B. Pembahasan}

Penelitian ini menggunakan teknik analisis regresi linier berganda dengan variabel bebas (independen) adalah Kompensasi dan Benefit (X), Variabel dependen dalam penelitian ini yakni Kepuasan kerja (Y). Berdasarkan pengolahan data yang dilakukan dengan menggunakan software SPSS 26 didapatkan hasil analisis sebagai berikut:

\section{Tabel 4}

Teknik Analisis Regresi Linier

\begin{tabular}{|c|c|c|c|c|c|c|c|}
\hline \multirow{2}{*}{\multicolumn{2}{|c|}{ Model }} & \multicolumn{3}{|c|}{$\begin{array}{l}\text { Unstandardized } \\
\text { Coefficiensts }\end{array}$} & \multirow{2}{*}{$\begin{array}{r}\text { Standardized } \\
\text { Coefficiensts } \\
\text { beta }\end{array}$} & \multirow[t]{2}{*}{$\mathrm{t}$} & \multirow[t]{2}{*}{ ig } \\
\hline & & \multicolumn{3}{|c|}{ Error } & & & \\
\hline \multirow[t]{3}{*}{1} & (con & & 11,469 & 1,257 & & 9.129 & 0.000 \\
\hline & \multicolumn{2}{|c|}{$\begin{array}{l}\text { Kompensas1 } \\
\text { dan benefit }\end{array}$} & 0,516 & 0,078 & 0,437 & 6,616 & 0,000 \\
\hline & \multicolumn{2}{|c|}{$\begin{array}{l}\text { Kepuasan } \\
\text { kerja }\end{array}$} & 0,366 & 0,081 & 0,292 & 4,499 & 0,000 \\
\hline \multicolumn{6}{|c|}{ a. Dependent Variabel : Kepuasan Kerja } & & \\
\hline \multicolumn{8}{|c|}{$\mathrm{R}=0,515$} \\
\hline \multicolumn{8}{|c|}{ R Square $=0,265$} \\
\hline \multicolumn{8}{|c|}{ Adjusted R Square $=0,257$} \\
\hline \multicolumn{6}{|c|}{ F hitung $=30,512$} & & \\
\hline
\end{tabular}


Signifikasi $=0.000$

1. Uji Parsial

Berdasarkan Tabel hasil analisis regresi berganda di atas dapat mengetahui pengaruh variabel secara parsial sebagai berikut:

a. Pengaruh variabel Kompensasi (X1) terhadap Kepuasan kerja.

Berdasarkan hasil olahan data diperoleh nilai t hitung sebesar 6,616 dan nilai signifikansi sebesar 0,000. Oleh karena nilai signifikasi sebesar 0,000 < 0,05, maka dapat disimpulkan bahwa Kompensasi berpengaruh signifikan terhadap Kepuasan kerja. Koefisien regresi bernilai positif menunjukkan bahwa pengaruh Kompensasi terhadap Kepuasan kerja bersifat positif. Dengan demikian hipotesis pertama yang menyatakan bahwa Kompensasi berpengaruh terhadap Kepuasan kerja, dapat diterima.

b. Pengaruh variabel Benefit (X2) terhadap Kepuasan kerja.

Berdasarkan hasil olahan data diperoleh nilai t hitung sebesar 4,499 dan nilai signifikansi sebesar 0,000. Oleh karena nilai signifikasi sebesar 0,000 < 0,05, maka dapat disimpulkan bahwa Benefit berpengaruh signifikan terhadap Kepuasan kerja. Dengan demikian hipotesis kedua yang menyatakan bahwa Benefit berpengaruh terhadap Kepuasan kerja, diterima.

2. Uji Stimultan

Pengujian hipotesis uji F digunakan untuk melihat apakah secara keseluruhan variabel bebas mempunyai pengaruh yang bermakna terhadap variabel terikat. Dari hasil pengujian regresi menunjukkan pengujian simultan diperoleh dari hasil pengolahan data menunjukkan nilai $\mathrm{F}$ hitung sebesar 30,512 dan nilai probabilitas signifikansi tersebut sebesar 0,000 dan tingkat $\alpha$ sebesar $5 \%$ , hal ini menunjukkan bahwa nilai signifikansi uji F 0,000 lebih kecil daripada nilai signifikansi 0,05. Artinya bahwa Kompensasi (X1) dan Benefit (X2) secara simultan berpengaruh signifikan terhadap Kepuasan kerja. Dengan demikian hipotesis ketiga yang menyatakan bahwa Kompensasi dan Benefit secara simultan berpengaruh terhadap Kepuasan kerja, dapat diterima.

3. Kontribusi Pengaruh

Tabel 5

Model Summary

\begin{tabular}{lllll}
\hline Variabel & Koefisien Beta & $\begin{array}{l}\text { Korelasi } \\
\text { Moment }\end{array}$ & Product & $\begin{array}{l}\text { Besar } \\
\text { Pengaruh }\end{array}$ \\
\hline Kompensasi & 0,437 & 0,421 & 0,184 \\
\hline Benefit & 0,297 & 0,274 & 0,081 \\
\hline & & Total & 0.265 \\
\hline
\end{tabular}

Pada tabel Model Summary diketahui nilai $\mathrm{R}$ square $=0,265$, artinya pengaruh Kompensasi dan Benefit secara simultan terhadap Kepuasan kerja sebesar 26,5\%. Nilai tersebut terdiri dari kontribusi Kompensasi sebesar 18,4\% 
dan kontribusi Benefit sebesar $8,1 \%$. Berdasarkan hasil tersebut, maka dapat disimpulkan bahwa pengaruh paling besar adalah variabel Kompensasi.

\section{Kesimpulan}

Berdasarkan hasil penelitian dan pembahasan, maka dapat ditarik beberapa kesimpulan yakni Kompensasi dan Benefit berpengaruh secara positif terhadap Kepuasan Kerja Pegawai Pemerintah Non PNS Pada Ditjen Kekayaan Intelektual. Berdasarkan hasil pengujian terhadap hipotesa yang diajukan kompensasi dan benefit secara bersama-sama memiliki pengaruh terhadap kepuasan kerja PPNPN di lingkungan Ditjen Kekayaan Intelektual. Berdasarkan penelitian yang dilakukan oleh penulis bahwa PPNPN di lingkungan Ditjen. 


\section{BIBLIOGRAFI}

Asmara, Anugerah Yuka, \& Rahayu, Sri. (2013). Meningkatkan Daya Saing Industri Kecil Menengah Melalui Inovasi Dan Pemanfaatan Jaringan Sosial: Pembelajaran Dari Klaster Industri Software Di India. Sustainable Competitive Advantage (Sca), 3(1). Google Scholar

Dessler, G. T. (2011). Human Resource Management. Singapore: Pearson Education South Asia Pte Ltd. Google Scholar

Hasibuan, Malayu S. P., \& Hasibuan, H. Malayu S. P. (2016). Manajemen Sumber Daya Manusia. Jakarta: Bumi Aksara. Google Scholar

Marwoto, Budi. (2014). Dukungan Inovasi Teknologi Dalam Peningkatan Daya Saing Industri Florikultura Nasional. Badan Penelitian Dan Perkembangan Pertanian. Kementerian Pertanian. Jakarta. Google Scholar

Mathis, R. L., \& Jackson, J. H. (2011). Personality Tests. Human Resource Management, 13th Ed., South-Western Cengage Learning, Usa, 227-228. Google Scholar

Moeheriono, Edi, \& Si, Dr M. (2012). Pengukuran Kinerja Berbasis Kompetensi. Jakarta: Raja Grafindo Persada. Google Scholar

Pridayanti, Ayunia. (2014). Pengaruh Ekspor, Impor, Dan Nilai Tukar Terhadap Pertumbuhan Ekonomi Di Indonesia Periode 2002-2012. Jurnal Pendidikan Ekonomi (Jupe), 2(2). Google Scholar

Rivai, Veithzal, \& Juavani, E. (2013). Manajemen Sumber Daya Manusia Untuk Perusahaan (Vol. V). Depok: Pt Raja Grafindo Persada. Google Scholar

Saputri, Azzahrani Giri. (2014). Analisis Kontribusi Usaha Kecil Menengah Di Kabupaten/Kota Provinsi Daerah Istimewa Yogyakarta. Jurnal Ekonomi (Je), 115. Google Scholar

Sugiyono. (2017). Sugiyono, Metode Penelitian. Penelitian. Google Scholar

Suwati, Yuli. (2013). Pengaruh Kompensasi Dan Motivasi Kerja Terhadap Kinerja Karyawan Pada Pt. Tunas Hijau Samarinda. Jurnal Ilmu Administrasi Bisnis, 1(1), 41-55. Google Scholar

Wibowo. (2013). Manajemen Sumber Daya Manusia Untuk Perusahaan. Jakarta: Pt. Raja Grafindo Persada. Google Scholar

Wibowo, Dimas Hendika, \& Arifin, Zainul. (2015). Analisis Strategi Pemasaran Untuk Meningkatkan Daya Saing Umkm (Studi Pada Batik Diajeng Solo). Jurnal Administrasi Bisnis, 29(1), 59-66. Google Scholar 
Analisis Pengaruh Kompensasi dan Benefit Terhadap Kepuasan Kerja Pegawai Pemerintah Non Pegawai Negeri Sipil pada Direktorat Jenderal Kekayaan Intelektual

Wibowo, W. (2014). Manajemen Kinerja (Edisi Keenam). Jakarta: Jakarta: Rajawali Pers. Google Scholar

Yulfiana, Dita, Yuliana, Yuliana, \& Suyuthie, Hijriyantomi. (2015). Kepuasan Kerja Karyawan Di Hotel Hotel Aliga Padang. Journal Of Home Economics And Tourism, 9(2). Google Scholar

\section{Copyright holder:}

Eka Kurniawan, Kusumo Bintoro (2021)

First publication right:

Syntax Literate: Jurnal Ilmiah Indonesia

This article is licensed under: 